\title{
MASONRY WALLS STRENGTHENED WITH VEGETAL FABRIC REINFORCED CEMENTITIOUS MATRIX (FRCM) COMPOSITES
}

\author{
LUIS MERCEDES ${ }^{1 *}$, ERNEST BERNAT-MASO $^{2}$ AND LLUIS GIL $^{1}$
}

\author{
${ }^{1}$ Department of Strength of Materials and Engineering Structures (RMEE) \\ Universitat Politècnica de Catalunya (UPC-BarcelonaTech) \\ Building TR45, Campus Terrassa UPC. Colom 11, 08222 Barcelona, Spain \\ email: luis.enrique.mercedes@upc.edu (*corresponding author); lluis.gil@upc.edu, litem.upc.edu \\ ${ }^{2}$ Department of Strength of Materials and Engineering Structures (RMEE). Serra Húnter Fellow \\ Universitat Politècnica de Catalunya (UPC-BarcelonaTech) \\ Building TR45, Campus Terrassa UPC. Colom 11, 08222 Barcelona, Spain \\ e-mail: ernest.bernat@upc.edu, litem.upc.edu
}

Keywords: Cyclic loading, Masonry walls; Cementitious matrix; Vegetal fibres; Hemp; Cotton; FRCM

\begin{abstract}
Fabric-reinforced cementitious matrices (FCRMs) are promising composite materials for the retrofitting and reinforcement of existing structures. In this study, vegetal meshes consisting of hemp and cotton coated with epoxy were manufactured and combined with a cementitious matrix to strengthen masonry walls. A synthetic glass fibre mesh was also tested. Several walls were manufactured, strengthened, and tested under cyclic loading. The results allow us to compare the performances of different mesh configurations in terms of size and materials. All strengthening solutions significantly increased shear strength capacity and the ability to dissipate energy compared to unreinforced walls. Further, all strengthened walls exhibited multi-track pattern distributions and achieved distortion capacity improvements of up to $300 \%$. Indicators of stiffness, energy dissipation, damping, residual deformation, and damage allow us to compare the strengthening performances of different solutions. The vegetal solutions provided superior efficiency compared to the glass-FRCM strengthened walls. Additionally, the use of a larger volume of vegetal fibres reduces the consumption of cement and can provide a sustainable solution. The main failure mechanism of the vegetal-FCRMs was debonding, which can be remedied by improvements to material interfaces.
\end{abstract}

\section{INTRODUCTION}

Unreinforced masonry structures are typically considered to be unsuitable in areas with high seismicity because their seismic performance is relatively variable. The reason for this variability can be explained based on the load-deformation relationship. Initially, masonry is rigid and exhibits negligible load effects. However, once peak deformation is reached, it typically fails in a fragile manner. In masonry without reinforcement, the redistribution of 
maximum stress is not possible, and local failures quickly escalate into global structure failures ${ }^{[1]}$.

Improving the tensile and shear strength of masonry is an attractive solution for improving its structural performance during seismic events. With this goal, numerous strengthening techniques have been developed throughout history to mitigate or prevent damage by seismic events, including well-researched strengthening techniques for fabricating fabric-reinforced cementitious matrices (FRCMs) ${ }^{[2,3]}$.

Despite the widely known efficiency of FRCMs for strengthening of masonry structures, the use of this technique is limited by the cost and environmental impact of producing the synthetic meshes that are commonly used in such composites. Additionally, based on the stiffness of these fibres, their ability to dissipate energy is limited. To overcome with these drawbacks, this paper presents vegetal fibre (more sustainable and less stiff compared to synthetic fibres) FRCMs as a strengthening technique for masonry walls.

Regarding the behaviour of walls strengthened by vegetal fibre FRCMs, there are numerous articles ${ }^{[4-6]}$ that have discussed the behaviour of this solution. The results demonstrate the excellent potential of vegetal fibre FRCMs as strengthening systems for masonry structures. The results obtained by Olivito et al. ${ }^{[5]}$ demonstrate the ductile behaviour and suitable ultimate tensile strength of flax-FRCMs and indicate that the tensile yield of flax-FRCMs is determined by the volume ratio of fibres used. On other hand, Menna et al. ${ }^{[7]}$ studied an innovative FRCM system utilising hemp meshes impregnated with epoxy resin. The impregnation of hemp yarns with epoxy resin allowed for better exploitation of the tensile properties of hemp fibres, and improved the mechanical properties of the masonry walls.
Based on the experimental results obtained for vegetal fibre FRCMs presented and analysed
in our previous paper ${ }^{8]}$, the type of fibre, mesh geometry, and CM to be used for the
strengthening of masonry walls were selected for this study.
Despite numerous tudies on to the use of vegetal fibre FRCMs to strengthen nasonry walls,

to the best of our knowledge there have been no studies on walls strengthened with hemp- and

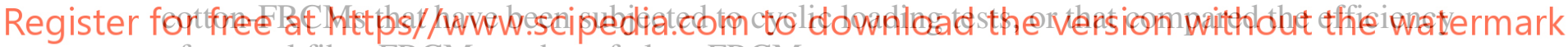
of vegetal fibre FRCMs to that of glass-FRCMs.

In this study, meshes with hemp and cotton yarns coated with epoxy were designed, manufactured, and combined a cementitious matrix to strengthen masonry wall specimens, which were subjected to cyclic loading tests. The structural responses of the walls were compared to those of unreinforced walls, wall strengthened by mortar alone, and walls strengthened by glass-FRCMs to validate the obtained results.

This paper presents innovative and sustainable composites of cementitious matrix and vegetal fibres as an alternative method for superior energy dissipation, distortion capacity, and shear strength of masonry walls subjected to cyclic loading.

\section{MATERIALS AND METHODS}

\subsection{Bricks}

Industrial bricks with nominal dimensions of $50 \mathrm{~mm} \times 128 \mathrm{~mm} \times 270 \mathrm{~mm}$ were used for manufacturing the walls. The mechanical properties of the bricks were determined on flexion and compression tests that were presented in a previous paper ${ }^{[9]}$, where the mean flexural tension was $4.37 \mathrm{MPa}$ and the mean compression strength was $27.93 \mathrm{MPa}$. 


\subsection{Mortars}

For the joints in the masonry walls, we utilised a mortar of pure natural lime NHL 3.5 in accordance with the EN 459-1 standard ${ }^{[10]}$ for the breathable construction and repair of walls, which is ideal for the restoration of historical works. control mortar specimens were subjected to flexion and compression testing. These tests were performed according to the EN 1015-11: 2000 standard ${ }^{[11]}$. where the mean flexural tension $3.73 \mathrm{MPa}$ and the mean compression strength was 4.68 MPa.

For strengthening the wall specimens, a single-component thixotropic mortar based on cement and synthetic resins reinforced with polyamide fibres (including silica fume) was utilised. This mortar complies with the requirements of type R3 as defined in the UNE-EN 1504-3 standard ${ }^{[12]}$. This mortar was selected because of the effectiveness it demonstrated in other studies ${ }^{[8]}$. The mechanical properties of this mortar were determinated by the same procedure that mortar joints properties. Where the mean flexural tension was $39.25 \mathrm{MPa}$ and the mean compression strength was $6.56 \mathrm{MPa}$.

\subsection{Meshes}

To compare the behaviour of vegetal fibre meshes to that of a synthetic fibre mesh, two types of vegetal fibres meshes were manufactured and compared to a commercial glass fibre mesh for strengthening the masonry walls. Glass fibre was chosen because it is one of the most commonly used synthetic fibres in FRCM strengthening systems.

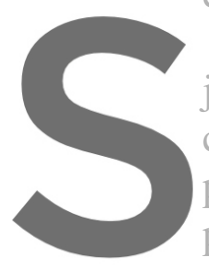

Vegetal fibre meshes justified by the fact that cotton-FRCM specimen previous study ${ }^{[8]}$. The previously determinated
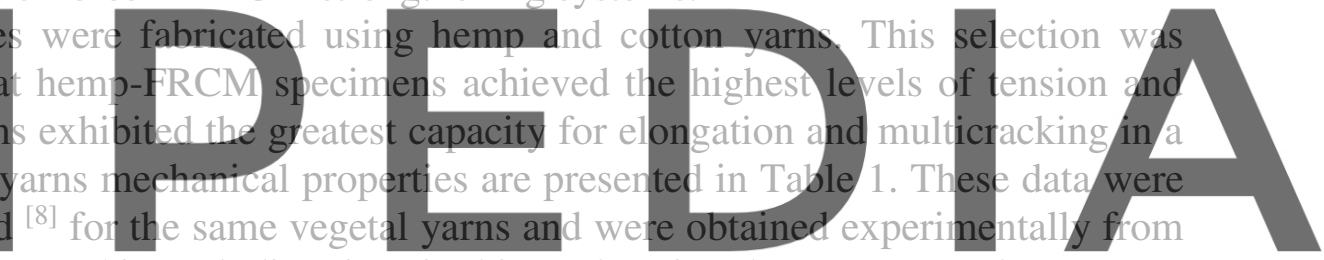
tests of 10 glass fibre yarns ( 5 in each direction) in this study using the same procedure.

Register for free at https//www.scipedia.com to download the version without the watermark

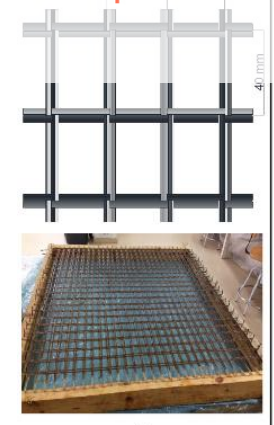

(a)

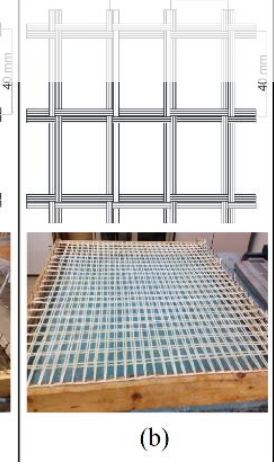

(b)

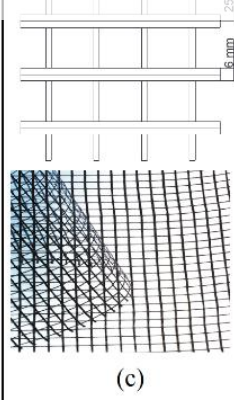

(c)

Figure 1. Reinforcing meshes: (a) hemp mesh, (b) cotton mesh, (c) glass mesh

A wooden rectangular support was assembled for use as a hand loom to manufacture meshes. The support is $90 \mathrm{~cm} \times 90 \mathrm{~cm}$ and has nails at its external boundaries (Figure 1). The nails are arranged at $3 \mathrm{~cm}$ increments in the warp direction, and $4 \mathrm{~cm}$ increments in the weft direction. The nails are useful for stretching and anchoring yarns, making it possible to weave meshes. Because the yarns had different diameters, the number of yarns used in each tuft differed for 
each type of mesh. The mesh geometry was designed by using the geometry of the commercial glass fibre meshes as a reference. The geometries and manufacturing parameters for these meshes are listed in Table 5.

After the meshes were woven, they were coated with epoxy resin using a brush. This deposited a superficial thin coat on the meshes. This was done to avoid fibre degradation within the mortar ${ }^{[13]}$, improve mechanical properties, and strengthen bonds between the meshes and matrices ${ }^{[8,14,15]}$. After one day of curing, the meshes were cut into pieces with dimensions of $87 \mathrm{~cm} \times 83 \mathrm{~cm}$.

The resin used to coat the yarns was an epoxy resin (MasterBrace P 3500) with low viscosity and high adhesion. This resin was selected based on its good interactions with FRCMs, which were observed in ${ }^{[8]}$.

Table 1. Mesh properties

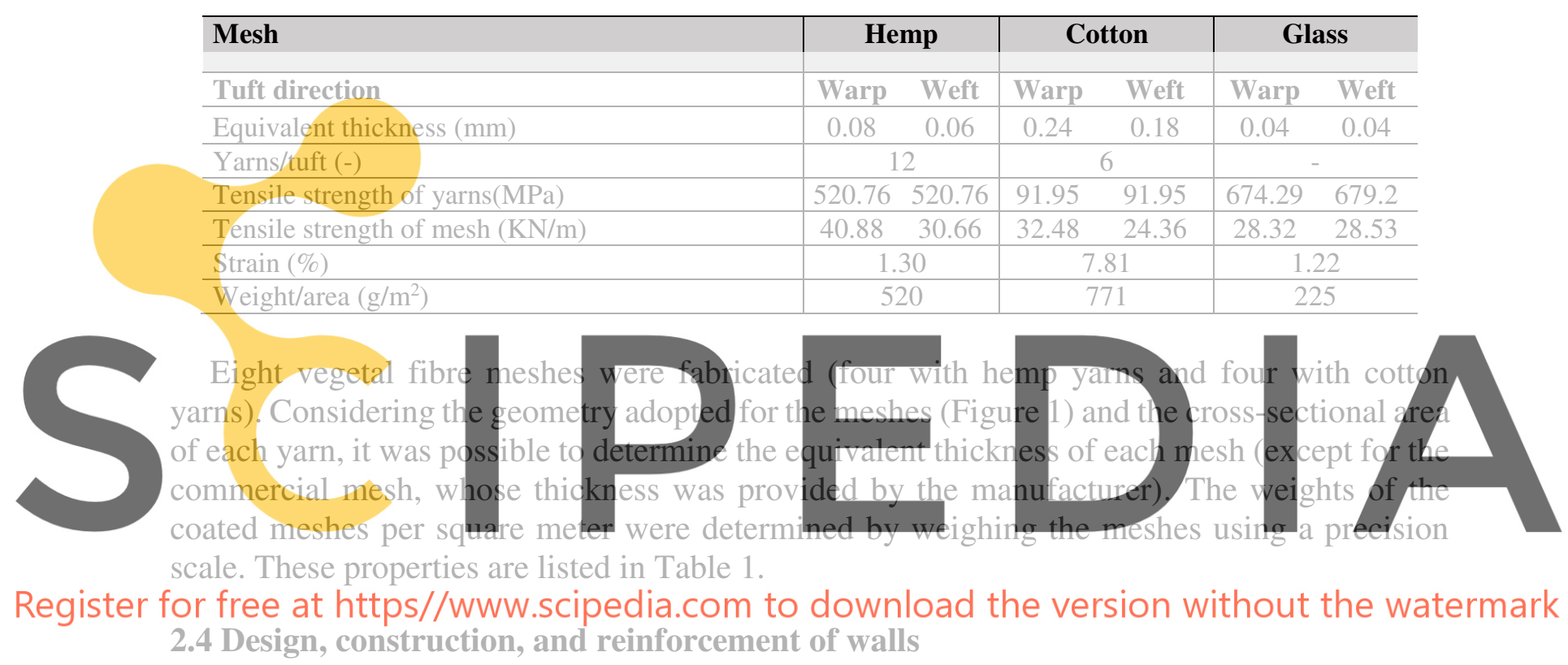

Walis with dimensions of $90 \mathrm{~cm} \times 100 \mathrm{~cm}$ were designed using the industrial bricks mentioned previously. The fabricated wall specimens were placed between metallic handling elements. These elements served as the bases and heads of the wall specimens to facilitate wall movement. They also acted as fastening elements for the test setup. Ten wall specimens were fabricated. Two were strengthened with hemp-FRCMs, two were strengthened with cottonFRCMs, two were strengthened with glass-FRCMs, two were strengthened with mortar alone, and two were left unreinforced.

To apply the FRCM strengthening systems to the walls, the faces to be strengthened were moistened and the first layer of mortar was applied. The meshes were then placed such that they adhered to the mortar. Finally, the strengthened specimens were finished by covering the meshes with another layer of mortar, leaving the meshes completely embedded. The nomenclature used to identify the walls was: unreinforced wall (WN), wall strengthened with only mortar (WMN), wall strengthened with hemp-FRCM (WH), wall strengthened with cotton-FRCM (WC) and wall strengthened with glass-FRCM (WG). 


\subsection{Test setup for cyclic loading tests}

The wall specimens were subjected to cyclic load tests ${ }^{[16]}$ to study the effectiveness of vegetal fibre FRCMs in terms of strengthening masonry buildings in high-seismicity areas.

The tests consisted of restraining the horizontal displacement of the wall tops and allowing in-plane displacement of the wall bottoms. A distributed compression load was applied to the wall tops and in-plane lateral cyclic displacement was applied to the wall bottoms. This test procedure was designed to determine the energy dissipation capacity, ductility, and cyclic shear strength of the tested wall specimens. The test speed and load cycles used in this test were based on the ASTM-E-2126-02a standard ${ }^{[2]}$. The detailed of this test setup is shown in the Figure 2.

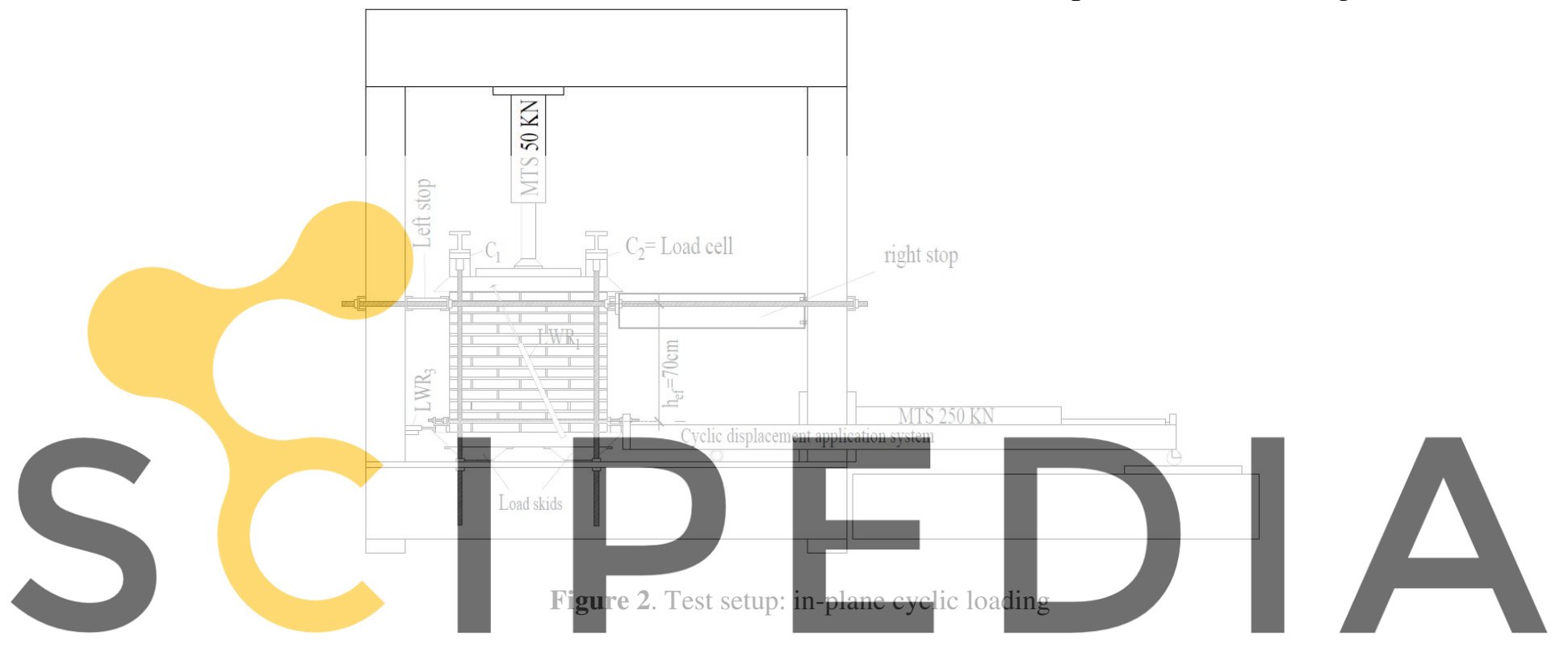

3 ANALYSIS AND DISCUSSION

Register for free at https//www.scipedia.com to download the version without the watermark testing described in Section 2.5 .

\subsection{Types of failure}

The failure of unreinforced walls (WN), walls strengthened with only mortar (WMN), and walls strengthened with glass fibre FRCMs (WG) was characterised by shear crack formation, resulting in two large diagonal cracks (Figure 3). In the case of the unreinforced walls, mixed breaks (joint and brick) were observed, mostly at joints, and in the case of walls strengthened only with mortar and with glass-FRCMs, more continuous cracking was observed based on the confinement provided by the strengthening system. In the case of the walls strengthened with glass-FRCMs, it was possible to observe fracturing of the mesh.

In the walls strengthened with vegetal fibre FRCMs, cracks were distributed diagonally across the FRCM system and there was detachment of the FRCMs near the corners of the walls, where local masonry failure was observed (see Figure 4)

The way in which cracks appeared in these specimens indicates a more favourable distribution of stress in the strengthening systems, as well as the possibility of dissipating additional energy through cracks. However, the fact that the FRCMs detached may indicate that 
the volume of fibres used affects connection to the matrix ${ }^{[6]}$ until the point of connection failure, resulting in the separation of these two components (masonry-FRCM) when the failure strength is exceeded. This may indicate the need to resort to anchoring method to improve the connection between FRCMs and masonry.

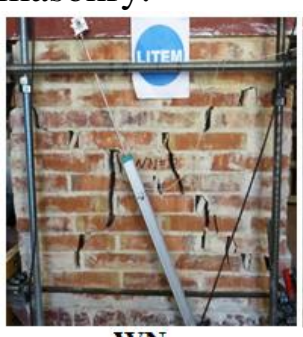

WN

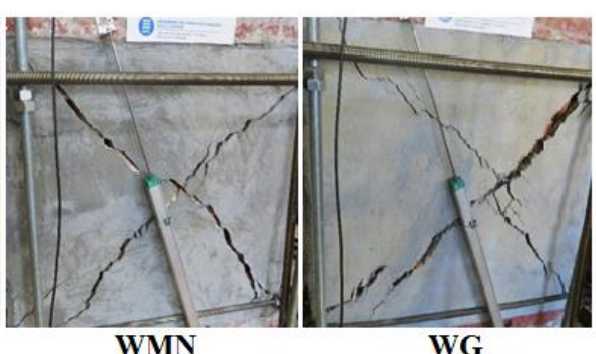

WMN
WG

Figure 3. Specimen failures: WN, WNM, and WG
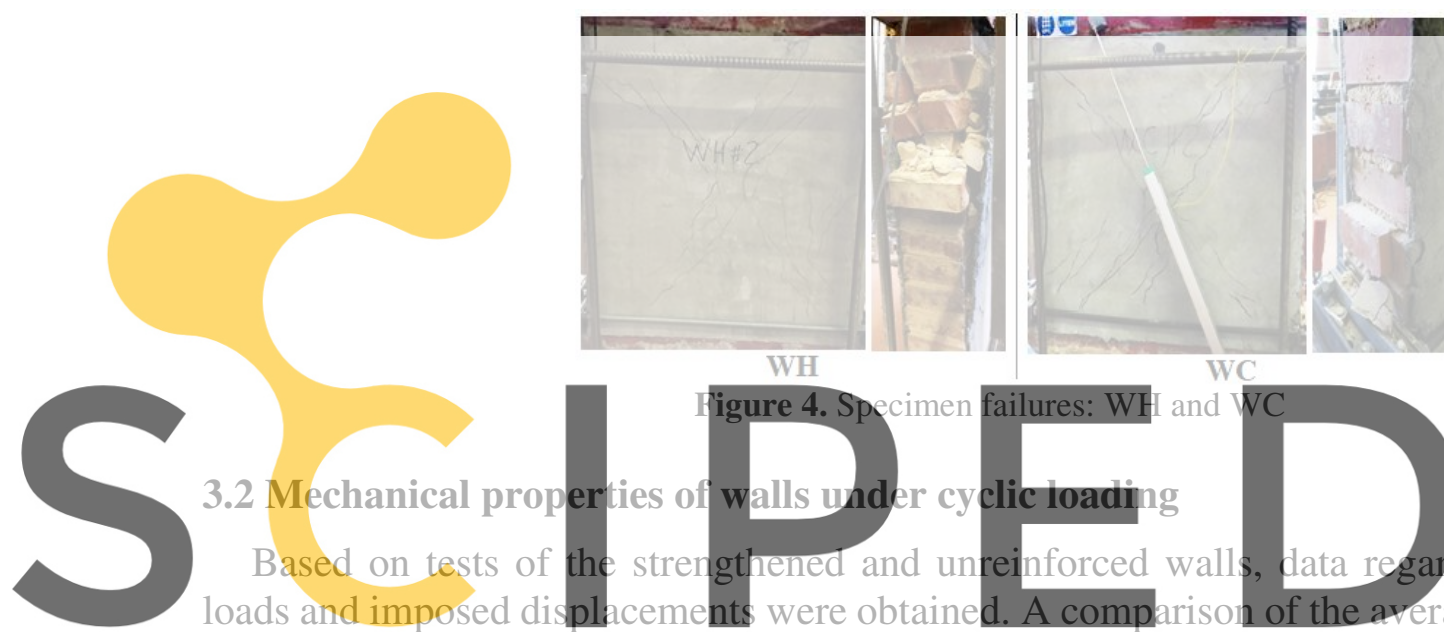

3.2 Mechanical proper
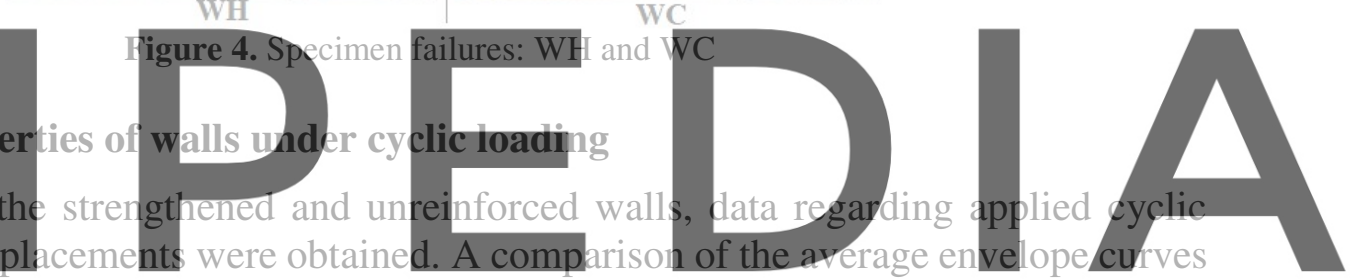

and bilinear model for each wall is also presented in Figure 5. One can see relatively open

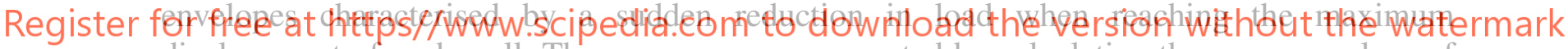
displacement of each wall. These curves were generated by calculating the average values of the two walls tested for each type of specimen. Distortion was obtained from the ratio of displacement to effective height $(700 \mathrm{~mm})$.
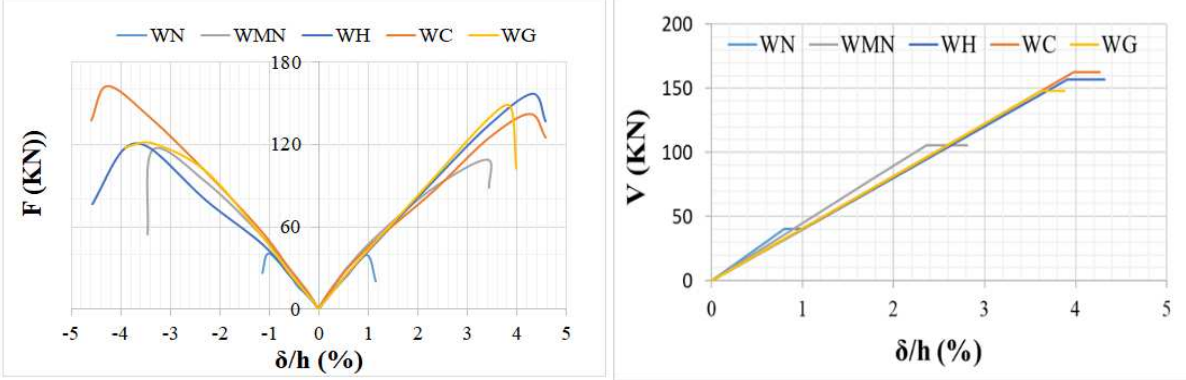

Figure 5. Envelope curves and bilinear models

A representative diagram of the properties calculated from the hysteresis diagrams defined by the envelopes and idealised bilinear model is presented in Figure 6. Based on this diagram, it was possible to identify parameters that are commonly used to define and analyse the behaviour of walls subjected to cyclic loads. 


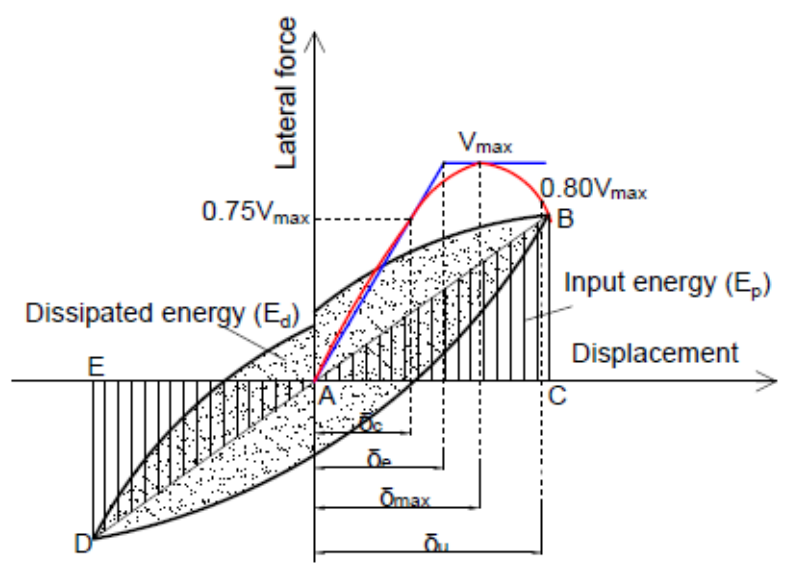

Figure 6. Details of the bilinear model and definition of energies ${ }^{[17,18]}$

The bilinear model adopted in this study was the one presented in ${ }^{[17]}$. This model was chosen because the enveloping curves were very open with relatively sharp reductions after reaching the maximum shear (see Figure 5). This model is defined by an equivalent shear equal to 0.75 times the maximum shear $\left(\mathrm{V}_{\max }\right), \mathrm{V}_{\max }$ itself, and the final shear equivalent to $0.80 \mathrm{~V}_{\max }$. Based on these values, the total failure of the structure, crack displacement $\left(\delta_{\mathrm{c}}\right)$, effective displacement $\left(\delta_{\mathrm{e}}\right)$ corresponding to the extrapolation of the limit state of cracking, displacement corresponding to $V_{\text {max }}$ and displacement corresponding to the final shear $\left(\delta_{\text {in }}\right)$ could be calculated. For this case based on the abrupt redı

The results of the cyct and maximum displace effective height ratio for each
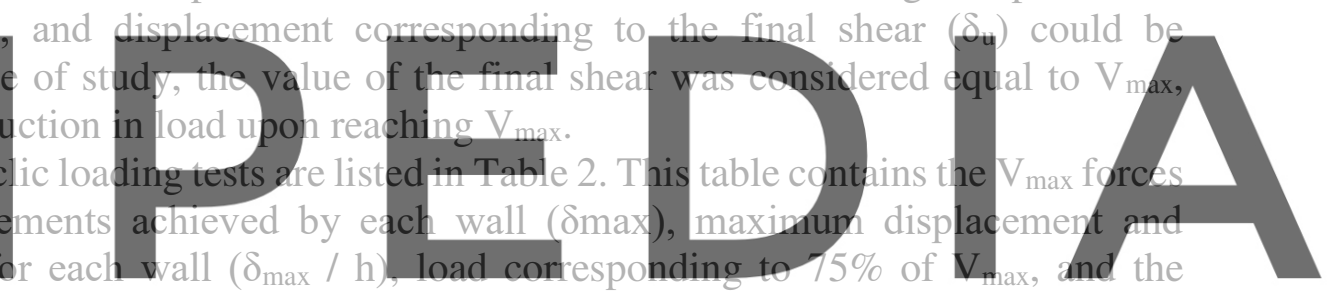

displacement at this point $(\delta \mathrm{c})$. Based on these values, it was possible to determine the shear

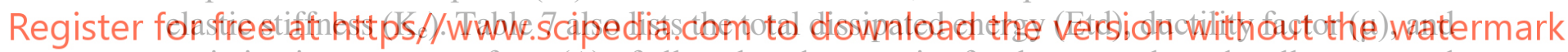
variation in percentage form $(\Delta)$ of all analysed properties for the strengthened walls compared to the unreinforced walls.

\subsubsection{Shear elastic stiffness $\left(\mathrm{K}_{\mathrm{e}}\right)$}

$\mathrm{Ke}$ is the elastic stiffness defined by the slope of the secant that passes from the origin to a point in the envelope curve at which the load is equal to $75 \%$ of $\mathrm{V}_{\max }$. Therefore, elastic stiffness can be calculated using the following equation:

$$
K_{e}=\frac{0.75 V_{\max }}{\delta_{c}}
$$

where $\delta \mathrm{e}$ is the equivalent displacement under the cracking load $\left(0.75 \mathrm{~V}_{\max }\right)$.

The results for elastic rigidity listed in Table 2 reveal a reduction in this parameter for all strengthened walls, especially those strengthened with FRCMs. This is a result of the greater capacity for deformation and energy dissipation provided by reinforcement. The stiffness differences between each type of specimen can be more fully appreciated based on Figure 5, which presents the bilinear models corresponding to each type of specimen. 


\subsubsection{Total energy dissipated}

Dissipated energy is the loss of energy in a structure during the period of time in which it is subjected to dynamic loads. This is equivalent to the involved area in the hysteresis cycles (see Figure 6). The total energy dissipated $\left(\mathrm{E}_{\mathrm{td}}\right)$ was calculated as the sum of the energy dissipated by each loading cycle $\left(\mathrm{E}_{\mathrm{di}}\right)$.

$$
E_{t d}=\sum_{i+1}^{n} E_{d i}
$$

Table 2. Results of cyclic loading tests

\begin{tabular}{|c|c|c|c|c|c|c|c|}
\hline Specimen & $\begin{array}{l}\mathbf{V}_{\max } \\
(\mathrm{KN})\end{array}$ & $\begin{array}{c}\mathbf{0 . 7 5 V _ { \text { max } }} \\
(\mathrm{KN})\end{array}$ & $\begin{array}{r}\boldsymbol{\delta}_{\max } \\
(\mathrm{mm})\end{array}$ & $\begin{array}{c}\boldsymbol{\delta}_{\max } / \mathbf{h} \\
(\%)\end{array}$ & $\begin{array}{c}\boldsymbol{\delta}_{\mathbf{e}} \\
(\mathrm{mmm})\end{array}$ & $\begin{array}{c}\mathbf{K}_{\mathbf{e}} \\
(\mathrm{KN} / \mathrm{mm})\end{array}$ & $\underset{(\mathrm{KN} / \mathrm{mm})}{\mathbf{E}_{\mathbf{d}}}$ \\
\hline & $1 \quad 2$ & 2 & 2 & & 1 & 1 & 1 \\
\hline 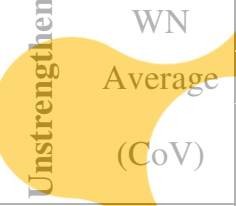 & $\begin{array}{c}45.56 \quad 35.52 \\
40.54 \\
(12.39 \%)\end{array}$ & $\begin{array}{c}34.17 \quad 26.64 \\
30.40 \\
(7.07 \%)\end{array}$ & $\begin{array}{c}7.95 \quad 6.11 \\
7.03 \\
(13.12 \%)\end{array}$ & 1.00 & $\begin{array}{c}4.13 \quad 4.27 \\
4.20 \\
(0.82 \%)\end{array}$ & $\begin{array}{c}8.27 \quad 6.22 \\
7.25 \\
(8.23 \%)\end{array}$ & $\begin{array}{c}498.75 \quad 470.37 \\
484.56 \\
(1.51 \%)\end{array}$ \\
\hline $\begin{array}{l}\text { WMN } \\
\text { Average } \\
(\mathrm{CoV}) \\
\Delta\end{array}$ & \begin{tabular}{|c|}
$116.22 \quad 95.52$ \\
105.87 \\
$(9.78 \%)$ \\
$161.15 \%$
\end{tabular} & $\begin{array}{c}87.16 \quad 71.64 \\
79.40 \\
(5.42 \%) \\
161.15 \%\end{array}$ & $3.5 \quad 15.82$ & & $\begin{array}{ll}15.30 & 9.51\end{array}$ & 5.77 .54 & 4742.70 \\
\hline 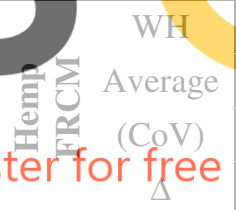 & $\begin{array}{c}146.08167 .0 \\
156.57 \\
(6.7 \%) \\
\text { at https } / / \mathrm{h}\end{array}$ & $\begin{array}{r}109.56125 \\
117.43 \\
(3.14 \%) \\
\text { W.scipeg }\end{array}$ & $\begin{array}{c}30.17 \quad 30.28 \\
30.22 \\
(0.18 \%) \\
\text { co }_{329.85 \%} \text { to }\end{array}$ & 32 & the $\frac{(0.11 \%)}{388.79 \% \text { rsior }}$ & $\begin{array}{c}5.72 \\
(3.24 \%) \\
\text { n withou }\end{array}$ & th the \\
\hline WC & 164.60160 .10 & $123.45 \quad 120.10$ & 30.6329 .03 & & $22.22 \quad 19.51$ & $5.55 \quad 6.15$ & $9752.38 \quad 10810.84$ \\
\hline 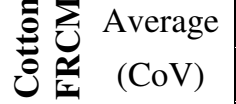 & $\begin{array}{l}162.35 \\
(1.38 \%)\end{array}$ & $\begin{array}{l}121.76 \\
(0.7 \%)\end{array}$ & $\begin{array}{c}29.83 \\
(2.68 \%)\end{array}$ & 4.26 & $\begin{array}{c}20.86 \\
(3.47 \%)\end{array}$ & $\begin{array}{c}5.85 \\
(2.43 \%)\end{array}$ & $\begin{array}{c}10281.61 \\
(2.45 \%)\end{array}$ \\
\hline$\Delta$ & $300.47 \%$ & $300.47 \%$ & $324.3 \%$ & & $396.74 \%$ & $-19.25 \%$ & $2021,84 \%$ \\
\hline WG & $147.45 \quad 148.00$ & 110.60111 .00 & $30.4 \quad 23.87$ & & $20.20 \quad 17.80$ & $5.50 \quad 6.25$ & $8659.70 \quad 5565,89$ \\
\hline 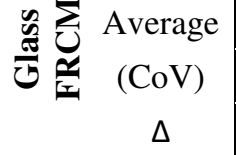 & $\begin{array}{l}147.73 \\
(0.19 \%) \\
264.4 \%\end{array}$ & $\begin{array}{l}110.79 \\
(0.09 \%) \\
264.4 \%\end{array}$ & $\begin{array}{c}27.13 \\
(12.04 \%) \\
285.93 \%\end{array}$ & 3.88 & $\begin{array}{c}19.01 \\
(3.48 \%) \\
352.56 \%\end{array}$ & \begin{tabular}{|c|}
5.85 \\
$(3.15 \%)$ \\
$-19.21 \%$
\end{tabular} & $\begin{array}{c}7112.77 \\
(13.90 \%) \\
1367.88 \%\end{array}$ \\
\hline
\end{tabular}

The main data to focus on in Table 2 are the large increases in shear strength and capacity to dissipate energy introduced by the strengthening systems. In Table 2, it can be observed that the strengthened walls that achieved the greatest shear strength are those strengthened by cotton-FRCMs, followed by hemp, glass, and mortar alone. This order is the same for dissipated energy. It can also be observed that the wall strengthened with mortar alone is able to increase 
shear strength by $116 \%$, but when the walls are strengthened with meshes, this increase also applies to the energy dissipation capacity.

The results in Table 2 demonstrate the effectiveness of reinforcement with vegetal fibre. Additionally, despite the hemp mesh having greater strength than the cotton mesh, the cottonFRCM system achieves greater shear strength and can dissipate more energy than the hempFRCM system. This can be attributed to the strain capacity of the cotton meshes. Cotton meshes have a greater deformation capacity than meshes of hemp and fiberglass, allowing the walls to reach greater shear loads and distortions, and exhibit greater energy dissipation capacity.

\subsubsection{Stiffness degradation}

Figure 7(a) presents the stiffness degradation of the walls as the displacement cycles proceed. Stiffness degradation was determined from the relationship between the average of the sums of absolute values of maximum shear load per cycle and average of the sums of absolute values of maximum displacement per cycle.

$$
K_{i}=\frac{\left|V_{i}^{-}+V_{i}^{+}\right|}{\left|\delta_{i}^{-}+\delta_{i}^{+}\right|}
$$

In Figure 7(a), it can be seen that in the case of the unreinforced walls, there is a sudden reduction in stiffness during the first several loading cycles. For the strengthened walls, a small reduction in stiffness occurs initially, then slow degradation proceeds until reaching the breaking point. This diagram reveals a more sudden loss in stiffness for the unreinforced walls walls strengthened witi indicates more fragile breakag matches the type of failure ob: 3.2.4 Damping factor
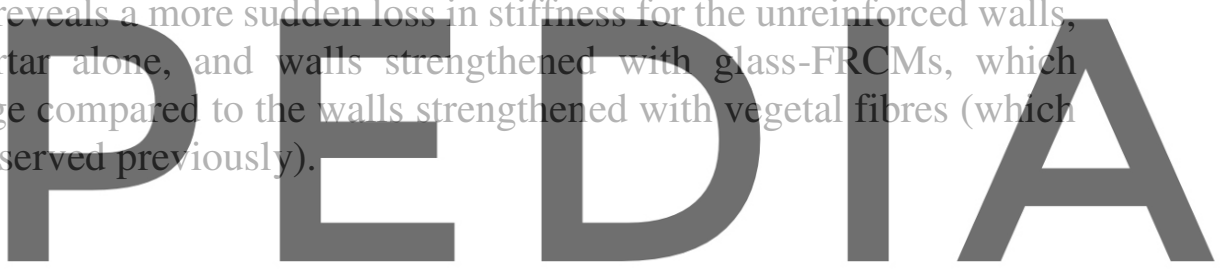

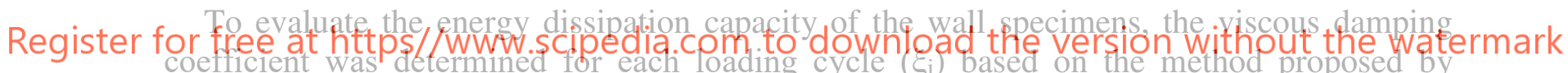
Jacobsen (1960). This parameter is defined as the capacity of a structure to dissipate input energy $\left(\mathrm{E}_{\mathrm{pi}}\right)$. Energy was calculated based on the average of the triangular areas defined in Figure 6 as follows:

$$
E_{p i}=\frac{\left|\operatorname{AreaABC}_{i}+\operatorname{AreaADE}_{i}\right|}{2}
$$

Once the input energy is calculated, it is possible to determine the damping coefficient for each cycle using the following equation:

$$
\xi_{i}=\frac{1}{2 \pi} \frac{E_{d i}}{E_{p i}}
$$

Figure 7(b) presents the evolution of the damping factor during the loading period. This figure reveals an almost constant damping factor until the point of cracking, which corresponds to the behaviour reported in other studies ${ }^{[19,20]}$, where damping was almost constant. However, once cracking occurs, this factor increases significantly for all specimens, which may be caused by friction between joints ${ }^{[19]}$. 
Figure 7(b) reveals better damping for the walls strengthened by vegetal fibres compared to the damping experienced by other walls because these walls provide more consistent and responsive damping compared to the other specimens.

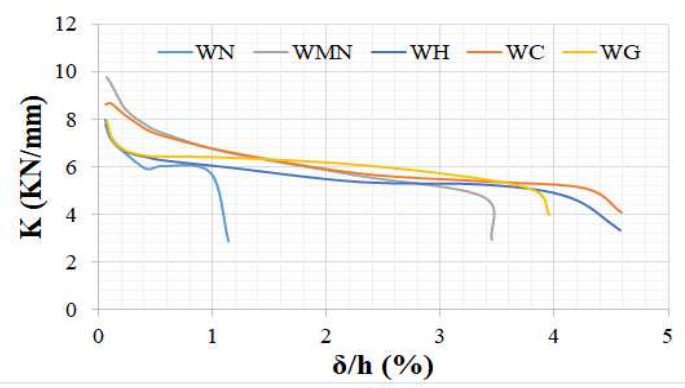

(a)

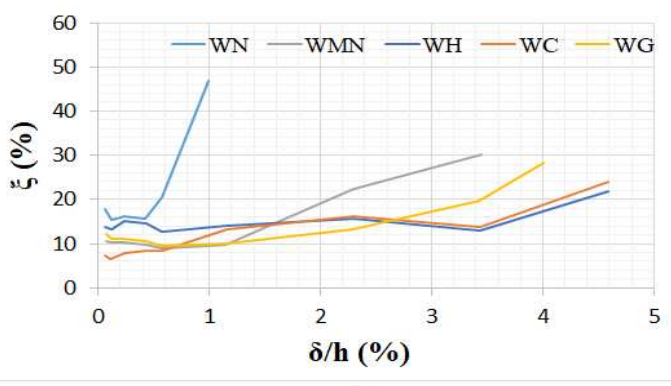

(b)

Figure 7. Wall properties during cyclic loading: (a) stiffness degradation, (b) damping factor

\subsubsection{Comparison of the effectiveness of vegetal fibre FRCMs and glass-FRCMs}

The results discussed above demonstrated that vegetal fibre FRCMs exhibit superior behaviour compared to glass fibre FRCMs under cyclic loading. Therefore, it is necessary to perform a comparative evaluation of the mechanical properties, specific weight, and cost of each type of FRCM.

Table 3 lists the volumes and weights of meshes and fibres calculated based on the geometrical dimensions meshes, which were acc

One noteworthy find on the large volume of $\mathrm{f}$ increased weight of the reinforce yarn densixies pres
y measured prior
this table is the re
the hemp-FRCY
rcement meshes esented previous
to reinforcement
eduction 1 n the
Ms $(0.5 \%)$ and co
and reduced we

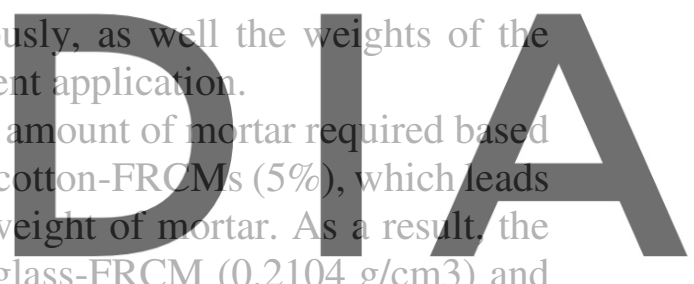
total weight of the cotton-FRCM is lower than those of the glass-FRCM $(0.2104 \mathrm{~g} / \mathrm{cm} 3)$ and

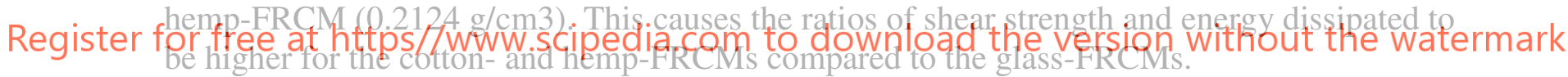

Table 3. Increase ratios of maximum shear and dissipated energy with FRCM specific weight

\begin{tabular}{l|c|c|c}
\hline FRCM & Hemp & Cotton & Glass \\
\hline Mesh Volume / FRCM volume (\%) & 1.26 & 5.67 & 0.77 \\
\hline Mortar Volume / FRCM volume (\%) & 98.74 & 94.33 & 99.23 \\
\hline Mesh weight / FRCM volume (g/cm3) & 0.005 & 0.007 & 0.002 \\
\hline Mortar weight / FRCM volume (g/cm3) & 0.207 & 0.198 & 0.208 \\
\hline FRCM weight / FRCM volume (g/cm3) & 0.2124 & 0.2055 & 0.2104 \\
\hline$\Delta$ Shear strength / FRCM specific weight (KN/g/cm3) & 546.33 & 592.63 & 509.53 \\
\hline$\Delta$ Dissipated energy / FRCM specific weight (KN-mm/ g/cm3) & 39628.27 & 47664.28 & 34359.45 \\
\hline
\end{tabular}

The comparisons made in this section confirm the superior effectiveness of the vegetal fibre meshes developed in this study compared to glass fibre meshes. However, the effectiveness of this type of mesh can be further improved through modifications to its geometry and to the 
volume of fibres used (failure caused by FRCM detachment can be associated with excessive reinforcement volume), as well as by using resin with a lower price, which would allow for greater mesh flexibility. Overall, sustainability improvements associated with the substitution of vegetal fibres for glass fibres are technically possible and economically feasible.

As a future line of research, it could be interesting to evaluate the possibility of superimposing vegetal meshes and the possibility to use some anchoring systems (possibly vegetal fibre FRP) that allows to avoid the FRCM detachment.

\section{CONCLUSIONS}

Based on the cyclic loading tests carried out in this study and analysis of the obtained results, the following conclusions can be derived:

- The types of failures of different specimens indicate a greater distribution of stresses for walls strengthened with vegetal fibre FRCMS. This is also related to their capability to dissipate more energy through multicracking patterns. However, the detachments of FRCMs may indicate an excessive volume of fibres and the need to use an anchoring method to improve the connection between FRCMs and masonry.

- The results reveal a greater increase in shear strength and energy dissipation capacity for walls strengthened with vegetal fibres compared to walls strengthened with glassFRCMs or mortar alone. The deformation capacity of vegetal fibre meshes (especially cotton fibres) allows them to reach higher shear strengths and displacements.

- The properties of degradation in stiffness, damping, residual deformation, and damage index were developed with greater efficiency in the walls strengthened with vegetal fibre FRCMs compared to the other specimens.

- The greater volume of fibres used in the vegetal fibre FRCMs reduced the amount of mortar required by approximately $0.5 \%$ for the hemp-FRCMs and approximately $5 \%$ for the cotton-FRCMs compared to the glass-FRCMs. This reduces the specific weight of the vegetal fibre FRCMs and alleviates the environmental effects caused by the cementitious matrix.

Acknowledgements The authors gratefully acknowledge financial support from the Ministerio de Economía y Competitividad of the Spanish Government and the European Regional Development Fund through the MULTIMAS project (ref. num. BIA2015-63882-P).

\section{REFERENCES}

[1] Días RLB. Vulnerabilidad y riesgo sísmico de edificios. Aplicación a entornos urbanos en zonas de amenaza alta y moderada. 2003:185-228.

[2] Babaeidarabad S, De Caso F, Nanni A. Out-of-Plane Behavior of URM Walls Strengthened with Fabric-Reinforced Cementitious Matrix Composite. Asce 2014;549:1-11. doi:10.1061/(ASCE)CC.

[3] Balsamo A, Di Ludovico M, Prota A, Manfredi G. Masonry walls strengthened with innovative composites. Am Concr Institute, ACI Spec Publ 2011;2:769-86.

[4] Snoeck D, Smetryns PA, De Belie N. Improved multiple cracking and autogenous healing in cementitious materials by means of chemically-treated natural fibres. Biosyst 
Eng 2015;139:87-99. doi:10.1016/j.biosystemseng.2015.08.007.

[5] Olivito RS, Cevallos OA, Carrozzini A. Development of durable cementitious composites using sisal and flax fabrics for reinforcement of masonry structures. Mater Des 2014;57:258-68. doi:10.1016/j.matdes.2013.11.023.

[6] Cevallos OA, Olivito RS. Effects of fabric parameters on the tensile behaviour of sustainable cementitious composites. Compos Part B Eng 2014;69:256-66. doi:10.1016/j.compositesb.2014.10.004.

[7] Menna C, Asprone D, Durante M, Zinno A, Balsamo A, Prota A. Structural behaviour of masonry panels strengthened with an innovative hemp fibre composite grid. Constr Build Mater 2015;100:111-21. doi:10.1016/j.conbuildmat.2015.09.051.

[8] Mercedes L, Gil L, Bernat-maso E. Mechanical performance of vegetal fabric reinforced cementitious matrix ( FRCM ) composites. Constr Build Mater 2018;175:161-73. doi:10.1016/j.conbuildmat.2018.04.171.

[9] Bernat E, Gil L, Roca P, Escrig C. Experimental and analytical study of TRM strengthened brickwork walls under eccentric compressive loading. Constr Build Mater 2013;44:35-47. doi:10.1016/j.conbuildmat.2013.03.006.

[10] Comite tecnico AEN/CTN 80. Cales para contrucción-parte 1: Definiciones, especificaciones y criterios de conformidad. 2016.

[11] UNE-EN 1015-11. Métodos de ensayo de los morteros para albañilería - Parte 11: Determinación de la resistencia a flexión y a compresión del mortero endurecido, 2000, p. 14.

[12] EN 1504-3. EN 1504-3 Products and systems for the protection and repair of concrete structures - Definitions, requirements, quality control and evaluation of conformity - Part 3: Structural and non-structural repair. Http://WwwAenorEs/ 2005.

[13] Micelli F, Aiello MA. Residual tensile strength of dry and impregnated reinforcement fibres after exposure to alkaline environments. Compos Part B Eng 2016. doi:10.1016/j.compositesb.2017.03.005.

[14] Donnini J, Corinaldesi V. Mechanical characterization of different FRCM systems for structural reinforcement. Constr Build Mater 2017;145:565-75. doi:10.1016/j.conbuildmat.2017.04.051.

[15] D'Antino T, Papanicolaou C. Mechanical characterization of textile reinforced inorganic-matrix composites. Compos Part B Eng 2017;127:78-91. doi:10.1016/j.compositesb.2017.02.034.

[16] American A, Standard N. Cyclic (Reversed) Load Test for Shear Resistance of Framed Walls for Buildings 1. Assembly n.d.:1-9.

[17] Ismail N, Ingham JM. In-plane and out-of-plane testing of unreinforced masonry walls strengthened using polymer textile reinforced mortar. Eng Struct 2016;118:167-77. doi:http://dx.doi.org/10.1016/j.engstruct.2016.03.041.

[18] Su Q, Cai G, Cai H. Seismic behaviour of full-scale hollow bricks-infilled RC frames under cyclic loads. Bull Earthq Eng 2016. doi:10.1007/s10518-016-0074-6.

[19] Hračov S, Pospíšil S, Garofano A, Urushadze S. In-plane cyclic behaviour of unfired clay and earth brick walls in both unstrengthened and strengthened conditions. Mater Struct 2015:3293-308. doi:10.1617/s11527-015-0720-5.

[20] Miranda L, Milosevic J, Bento R. Cyclic behaviour of stone masonry walls strengthened by grout injection. Mater Struct 2017;50:47. doi:10.1617/s11527-016-0911-8. 